DOCUMENTS

pour l'histoire

des techniques
Documents pour l'histoire des techniques

Nouvelle série

$15 \mid 1^{\text {er }}$ semestre 2008

Minorités et circulations techniques du Moyen-Âge à l'époque Moderne

Frédérique Audouin-Rouzeau, Sylvie Beyrieséd., Le travail du cuir de la Préhistoire à nos jours, actes des XXII ${ }^{e}$ rencontres internationales d'archéologie et d'histoire d'Antibes (18-20 octobre 2001)

Antibes, APDCA, 2002, 496 pages.

André Guillerme

\title{
CpenEdition
}

Journals

Édition électronique

URL : http://journals.openedition.org/dht/1050

DOI : $10.4000 /$ dht. 1050

ISSN : 1775-4194

Éditeur :

Centre d'histoire des techniques et de l'environnement du Cnam (CDHTE-Cnam), Société des élèves du CDHTE-Cnam

Édition imprimée

Date de publication : 1 juin 2008

Pagination : 211-212

ISBN : 978-2-95-30779-1-9

ISSN : 0417-8726

Référence électronique

André Guillerme, «Frédérique Audouin-Rouzeau, Sylvie Beyrieséd., Le travail du cuir de la Préhistoire à nos jours, actes des XXII rencontres internationales d'archéologie et d'histoire d'Antibes (18-20 octobre 2001) », Documents pour l'histoire des techniques [En ligne], 15 | $7^{\text {er }}$ semestre 2008, mis en ligne le 22 octobre 2010, consulté le 21 septembre 2020. URL : http://journals.openedition.org/dht/1050 ; DOI : https://doi.org/10.4000/dht.1050

Ce document a été généré automatiquement le 21 septembre 2020.

(c) Tous droits réservés 


\section{Frédérique Audouin-Rouzeau, Sylvie Beyrieséd., Le travail du cuir de la Préhistoire à nos jours, actes des XXII rencontres internationales d'archéologie et d'histoire d'Antibes (18-20 octobre 2001)}

Antibes, APDCA, 2002, 496 pages.

\section{André Guillerme}

\section{RÉFÉRENCE}

Frédérique Audouin-Rouzeau, Sylvie Beyrieséd., Le travail du cuir de la Préhistoire à nos jours, actes des XXII rencontres internationales d'archéologie et d'histoire d'Antibes (18-20 octobre 2001), Antibes, APDCA, 2002, 496 pages.

Une trentaine de contributions, près de cinq cents pages concises et originales à propos d'un matériau, d'un non-tissé qui a fait la préhistoire et l'histoire de l'humanité habillement, ameublement, transport, guerre et paix, loisirs, chasse, faits et gestes, chausses et gants, chapeaux et colles, écritures et enluminures. Un matériau qui a fait aussi les révolutions industrielles : la première - la transmission mécanique, le luxe des chapeaux, la jusée de Séguin qui produit un million de peaux par an et assure la marche des armées anglaises en Inde et des révolutionnaires françaises à travers l'Europe - et la seconde - l'emploi du chrome en place du tan. La fabrication du cuir pollue; les tanneries sont exclues de l'agglomération française pour leur incommodité par le décret du 15 octobre 1810, mais le procédé au chrome qui se déploie dans les années 1880 détruit la faune piscicole. 
2 Une matière qui n'a pas attiré beaucoup les historiens et encore moins les humanistes des techniques ou de l'environnement - archéologues, ethnologues, historiens, sociologues. Ces actes d'ethnoarchéologie et d'ethnohistoire n'entrouvrent pas une fenêtre, ils donnent sur un large panorama, un paysage de métiers, complexe, dense et « animé ».

3 Première contribution, très technique et pédagogique, "L'évolution des techniques de fabrication du cuir et problèmes de conservation » de Claire Chahine, permet au nonspécialiste de jauger l'élaboration du matériau depuis la peau verte, les manipulations, la biochimie du milieu humide. À la suite, les fouilles archéologiques prouvent l'omniprésence du cuir dans les sociétés méditerranéennes et africain : matériau biodégradable, il n'a pu se conserver qu'en milieu sec et neutre, tombes, grottes. Au III millénaire, au Soudan, en Éthiopie, il est travaillé à la pierre, à l'os, aux résines ; il est déjà très élaboré - sandale, habillement, linceul, baratte, jouet - et doté de valeurs esthétiques, symboliques - le blanc du prêtre, le rouge du guerrier, «Les cuirs du mort » de Pascal Plattet - et économiques. Plus tard, il constitue, aux Canaries comme au grand Sahara, l'habitat - une centaine de peaux pour couvrir une tente touarègue et étend son usage - tapis de prières.

4 Peaux de poissons - très riche contribution de Victor D’Iatchenko et François David à propos des cuirs sibériens des Toungouzes - ou de mammifères font cuir. Trois phases dictent le geste de fabrication : l'épilage, le tannage et le corroyage. La première libère l'épiderme après séchage et traitements au lait, au son ou à la chaux pour faciliter l'épilation ou le grattage. La seconde gonfle la peau avec des ferments et des acides organiques - écorces fermentées, fientes, urine - et la travaille pour l'assouplir ; ici il faut contrôler soigneusement le temps pour donner de la qualité. La dernière l'imbibe de corps gras et la fait luire et reluire pour l'imperméabiliser et la teindre. Marie Leguilloux rapporte très bien cette division du travail à propos de l'« officia coriaria » de Pompéi.

5 Métiers parfois masculins (Europe historique), plus souvent féminins (Maroc, Éthiopie), moyennement nobles - moins que la forge - et souvent claniques, tanneurs, corroyeurs, mégissiers (peaux alunées), pelletiers, hongroyeurs, parcheminiers, maroquiniers, chamoiseurs, consomment beaucoup d'eau. Leurs rapports avec l'animalité, la bestialité, les positionnent aux limites de l'urbanité - « Usages religieux du vêtement de fourrure dans l'Antiquité » de Dominique Lavergne - dans la société romaine. Mais dans l'Occident chrétien, le cuir devient matière guerrière, le tannage végétal romain prend de l'importance. Le Moyen Âge urbain déroule ses canaux pour lui : les belles fouilles des ateliers des tanneurs à Troyes (Aube) en inventent les techniques d'élaboration, celles de la place du Neuf-Bourg à Valenciennes en révèlent les usages cordonniers. Les rares textes techniques médiévaux disponibles sont enfin recensés et explicités (Ricardo. Cordoba de la Llave) et comparés à la diversité des métiers de la période suivante qu'énumère Eva Halasz-Csiba. Deux contributions importantes concernent la fourrure, signe d'aisance urbaine : celle de R. Delort sur les techniques de pelleterie en Occident (XIV et $\mathrm{XV}^{\mathrm{e}}$ siècles), notamment dans les Flandres, celle, très éloquente, d'Urzsula Sowina qui fouille les testaments des bourgeois cracoviens pour y découvrir pourpoints, robes, manteaux et autres sur-vêtements, tout de fourrure. Françoise Piponnier aborde avec son talent de miniaturiste «Les ateliers du cuir... à Dijon (fin $\mathrm{XIV}^{\mathrm{e}}-\mathrm{XV}^{\mathrm{e}}$ siècles) » pour analyser cinq inventaires de tanneurs et deux de parcheminiers - biens, outils, peaux. Témoin du quotidien comme des arts premiers, le 
cuir mérite reconnaissance, reconstitution et conservation. Cette dernière question est largement abordée par les experts. Les expériences du British Museum présentées par Edouard Wills montrent que le pliantex, une résine polyacrylique, paraît être le meilleur conservateur des cuirs anciens.

\section{AUTEURS}

\section{ANDRÉ GUILLERME}

CDHTE-Cnam 